\title{
10 health stories that mattered: Dec. 9-13
}

- Federal Health Minister Rona Ambrose and other G8 health ministers vowed to find a cure or "disease-modifying therapy" for dementia by 2025 and "increase collectively and significantly the amount of funding for dementia research to reach that goal." The ministers also committed to create an "envoy" of international experts to coordinate fundraising.

- The federal government introduced new patient safety legislation that would enable Health Canada to recall unsafe prescription drugs, mandate adverse drug reaction reporting and compel drug companies to conduct postmarket approval testing on products.

- Veterans Affairs Canada announced it will simplify how seriously disabled veterans apply for health benefits. The department vowed to streamline the application process through "enhanced online navigation, reusing information already gathered from Veterans, and simplifying forms."

- Ontario is reinstating access to essential and urgent health care for refugee claimants through a new program called the Ontario Temporary Health Program. The federal government cut health funding for refugees in 2012. The Ontario government says it will "send the federal government the bill to pay for the program."

- There are plans to open four supervised injection sites in Montréal, Quebec, reports CBC News. It is estimated that it will cost $\$ 3.2$ million to get the service started and annual costs will be about $\$ 2.7$ million.

- Nova Scotia will recruit more psychiatrists to treat youth after a review of mental health services in the province highlighted gaps in care for the growing number of young people seeking help, reported CTV News. The review found older teens are frequently shuffled between adult and child services, resulting in fractured care and unnecessary treatment delays.

- New Brunswick unveiled a new prescription drug plan to provide affordable coverage for people who don't have insurance through their employers. Under the plan, residents pay a yearly premium of $\$ 800-\$ 2000$ based on income, and a maximum copay of $\$ 30$ per prescription at the pharmacy.
- Prescription painkiller use in British Columbia is a troubling $25 \%$ higher than the national average for Canada, researcher Steve Morgan warned CTV News. There were 512 painkiller prescriptions written per 1000 British Columbians last year, compared to 422 per 1000 Canadians, according to research by Morgan and colleagues.

- An Ontario private member's bill would allow children with asthma to carry inhalers with them in school. The legislation, which calls for school boards across the province to implement asthma management plans, was introduced after a 12-year-old boy died from an asthma attack before he could retrieve his inhaler from a locked school office.

- A new school of public health was inaugurated in Montréal, Quebec. L'École de santé publique de l'Université de Montréal is the first of its kind in Quebec and one of only three schools of public health in Canada, reports the Montreal Gazette. - Lauren Vogel and Roger Collier, CMAJ

CMAJ 2014. DOI:10.1503/cmaj.109-4684 